\title{
A Comparative Study on Micellar and Solubilizing Behavior of Three EO-PO Based Star Block Copolymers Varying in Hydrophobicity and Their Application for the In Vitro Release of Anticancer Drugs
}

\author{
Bijal Vyas ${ }^{1}$, Sadafara A. Pillai ${ }^{1}$, Anita Bahadur ${ }^{2}$ and Pratap Bahadur ${ }^{1, *}$ \\ 1 Department of Chemistry, Veer Narmad South Gujarat University, Surat 395007, India; \\ vyasbijal80@gmail.com (B.V.); sadafarashirgar@gmail.com (S.A.P.) \\ 2 Department of Zoology, PT Sarvajanik College of Science, Surat 395001, India; anita26p@gmail.com \\ * Correspondence: pbahadur2002@gmail.com; Tel.: +91-987-913-2125
}

Received: 16 December 2017; Accepted: 13 January 2018; Published: 15 January 2018

\begin{abstract}
The temperature and $\mathrm{pH}$ dependent self-assembly of three star shaped ethylene oxide-propylene oxide (EO-PO) block copolymers (Tetronics ${ }^{\circledR} 304,904$ and 908) with widely different hydrophobicity was examined in aqueous solutions. Physico-chemical methods viz. viscosity, cloud point, solubilization along with thermal, scattering and spectral techniques shows strongly temperature and salt dependent solution behavior. T304 possessing low molecular weight did not form micelles; moderately hydrophilic T904 remained as micelles at ambient temperature and showed micellar growth while very hydrophilic T908 formed micelles at elevated temperatures. The surface activity/micellization/solubilization power was favored in the presence of salt. The copolymers turn more hydrophilic in acidic $\mathrm{pH}$ due to protonation of central ethylene diamine moiety that hinders micelle formation. The solubilization of a model insoluble azo dye 1-(o-Tolylazo)-2-naphthol (Orange OT) and hydrophobic drugs (quercetin and curcumin) for copolymer solutions in aqueous and salt solutions are also reported. Among the three copolymers, T904 showed maximum solubility of dye and drugs, hence the in vitro release of drugs from T904 micelles was estimated and the effect on cytotoxicity of loading the drugs in T904 micelles was compared with the cytotoxicity of free drugs on the $\mathrm{CHO}-\mathrm{K} 1$ cells. The results from the present work provide a better insight in selection of Tetronics ${ }^{\circledR}$ for their application in different therapeutic applications.
\end{abstract}

Keywords: Tetronics; micelles; in vitro release; anticancer drugs; solubilization; drug delivery

\section{Introduction}

Block copolymers contain at least two incompatible blocks and thus show micro domain formation in solid state and self-assembly in selective solvents; these properties coupled with advances in polymerization techniques have made polymeric surfactants highly useful materials [1-3]. Pluronics ${ }^{\circledR}$ and Tetronics ${ }^{\circledR}$ are commercially available poly(ethylene oxide) (PEO)-poly(propylene oxide) (PPO) block copolymers with unique temperature dependent micellization/surface activity and reversible thermorheological behavior that make these substances widely useful in cosmetic/detergents/food/pharmaceutical industries. Due to their nontoxicity and low immune response, some of these copolymers are now Food and Drug Administration (FDA) approved. Their emerging applications in fabrication of mesoporous materials [4,5], synthesis of nanoparticles [6,7] and as nanocarriers for drug delivery systems [8-12] have generated more interest in researchers [13,14]. Strongly temperature dependent micellization and gelation of these amphiphilic copolymers have 
been thoroughly examined in the last few decades though mostly on linear PEO-PPO-PEO triblock copolymers and there exist several reviews $[1,15,16]$. However, only a few authors have reported on the aqueous solution behavior of their star shaped counterparts [17-30].

Tetronics ${ }^{\circledR}$ (also known as poloxamines) present an X-shaped structure made of an ethylenediamine central group bonded to four chains of PPO-PEO blocks. Tetronics ${ }^{\circledR}$ are synthesized by the sequential reaction of the acceptor ethylenediamine molecule first with propylene oxide (PO) and then with ethylene oxide (EO) precursors, resulting in a four-arm PEO-terminated molecular structure (Figure 1). The unique structure of Tetronics ${ }^{\circledR}$ provides them with multistimulus responsiveness. In this context, the two tertiary amine central groups play an essential role in conferring thermodynamic stability and $\mathrm{pH}$ sensitivity. The micelle formation of Tetronics ${ }^{\circledR}$ is slightly different from the Pluronics ${ }^{\circledR}$ as the former also show some pH responsiveness. Like Pluronics ${ }^{\circledR}$, a slight increase in the temperature can induce surface activity/micellization/gelation due to the dehydration of PPO and PEO blocks. The central diamine unit in Tetronics ${ }^{\circledR}$ molecule is $\mathrm{pH}$ sensitive and can be protonated in acidic solution. Low $\mathrm{pH}$ and low temperature may thus hamper micellization. Albeit still limited, the studies on Tetronics ${ }^{\circledR}$ have revealed their potential in different fields. These cover broad area of applications including petroleum industries where these are used in comparatively higher concentrations either as de-emulsifiers or as antifoaming agents [31,32], as an important ingredient in contact lens washing solutions [33,34], in pharmaceutical and biomedical field as constituents of transdermal formulations [35], in nanoparticle engineering [36] and as tissue scaffoldings [37,38]. De Lisi et al. [39] studied the self-assembly and oil solubilizing behavior of T1107 as a function of temperature and $\mathrm{pH}$ and revealed improved solubilization and oil induced micellization, which can be tuned further by varying temperature and $\mathrm{pH}$. Larrañeta et al. [40] synthesized different types of gels by the addition of $\alpha$-cyclodextrin in the T904 solutions for sustained drug delivery applications. González-Gaitano et al. [41] explored the effect of different native and modified cyclodextrins on T904 micelles and revealed that most substituted cyclodextrins induced micellar breakdown while native cyclodextrins promoted the formation of inclusion complexes. Recently, Poellmann [42] based on his study on T1107 with denatured hen egg white lysozyme found a potential application of T1107 as a synthetic chaperone that enhances the molecular repair phenomenon in cells. Gonzalez-Lopez et al. [20] explored the micellization of different Tetronics ${ }^{\circledR}$ with varying structural features in acidic media. There are also contributions from our group concerning the effect of different additives on micellar behavior of Tetronics ${ }^{\circledR}[43-49]$.

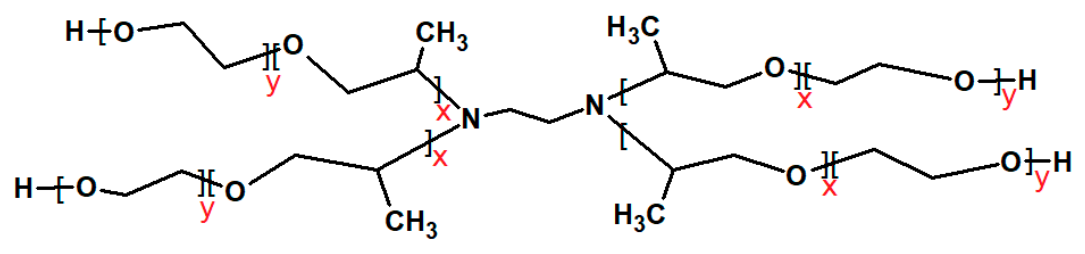

Figure 1. General structure of Tetronics ${ }^{\circledR}$.

It can be understood from the above literature survey that reports on individual behavior of different Tetronics ${ }^{\circledR}$ in the presence of variety of additives have been published in literature. However, a systematic study comparing the self-assembly of different Tetronics ${ }^{\circledR}$ on the basis of their molecular architecture in aqueous and salt solutions is still missing, to the best of our knowledge. The knowledge attained from this work can be useful in anticipating the performance of the copolymer for the desired application. With this view point, we have tried to elucidate the aggregation behavior of three Tetronics ${ }^{\circledR}$, mainly T304, T904 and T908 incorporated with different \%EO (in case of T904 and T908, $\% \mathrm{PEO}=40$ and 80) and with different molecular weight (in the case of T304 and T904, but with same $\% \mathrm{PEO}=40$ ). This study was further extended by determining the solubility of a hydrophobic dye (orange-OT) and drugs (quercetin and curcumin) in micelles under different solution conditions. T904 with a moderately hydrophobic character showed a maximum solubility. Hence, in vitro release of the 
hydrophobic drugs from its micelles was measured and the influence on cytotoxicity of the drugs being loaded in micelles was compared with the free drugs. The findings of this work will be highly useful for the proper exploitation of copolymer micelles in several industrial and pharmaceutical applications.

\section{Materials and Methods}

Tetronics ${ }^{\circledR}$ 304, 904 and 908 were gift samples from the BASF Corporation (Parsippany, NJ, USA) and were used as received. The structural formula for Tetronics ${ }^{\circledR}$ block copolymers (Figure 1) and molecular/physico-chemical properties are shown in Table 1.

Table 1. Structural properties of different Tetronics ${ }^{\circledR}$.

\begin{tabular}{|c|c|c|c|c|c|c|c|}
\hline Tetronic $^{\circledR}$ & $M_{\mathrm{w}}^{\mathrm{a}}$ & $\mathrm{N}_{\mathrm{EO}}$ & $\mathrm{N}_{\text {PO }}$ & HLB $^{a}$ & $\mathrm{CP}{ }^{\mathrm{a}}\left({ }^{\circ} \mathrm{C}\right)$ & $\mathrm{pKa}_{1}{ }^{\mathrm{a}}$ & $\mathrm{pKa}_{2}{ }^{\mathrm{a}}$ \\
\hline T304 & 1650 & 3.7 & 4.3 & $12-18$ & 72 & 4.3 & 8.1 \\
\hline T904 & 6700 & 15 & 17 & $12-18$ & 78 & 4.0 & 7.8 \\
\hline T908 & 25,000 & 114 & 21 & $>24$ & $>100$ & 5.2 & 7.9 \\
\hline
\end{tabular}

Sodium chloride (Merck, Mumbai, India, analytical grade), the drugs, quercetin and curcumin (Sigma Aldrich, Mumbai, India) and the dye, Orange-OT (TCI Chemicals, Chennai, Tamilnadu, India) were used as received. Solutions for dynamic light scattering (DLS) measurements were prepared in nano-pure water obtained from Millipore Milli-Q purification system (Mumbai, India). $\mathrm{D}_{2} \mathrm{O}(99.9 \%)$ obtained from Sigma Chemical Company (Mumbai, India) was used for nuclear magnetic resonance (NMR) and small-angle neutron scattering (SANS) measurements. The chinese hamster ovary (CHO-K1) cell line for the toxicity assay was procured from American Type Culture Collection (ATCC).

\subsection{Methods}

\subsubsection{Cloud Point (CP)}

Cloud points were determined by visual observation of the turbidity of the solution (in $20 \mathrm{~mL}$ glass vials) immersed in a temperature controlled water bath. The solutions were stirred with a magnetic bar while being heated. All of the measured $\mathrm{CP}$ values were reproducible up to $\pm 1.0^{\circ} \mathrm{C}$.

\subsubsection{Surface Tension}

The surface tension measurements were done with a KRUSS Easy Tensiometer from Kruss Gmbh (Hamburg, Germany) using the Wilhelmy plate method. The surface tension of double distilled water $71.8 \mathrm{mN} \cdot \mathrm{m}^{-1}$ at $25.0 \pm 0.1{ }^{\circ} \mathrm{C}$ was used to calibrate the instrument. The surface tension of each solution was measured by successive additions of the stock solutions in double distilled water after thorough mixing and equilibration. The series of measurements were repeated at least three times. The reproducibility of surface tension measurements is estimated to be within $\pm 0.2 \mathrm{mN} \cdot \mathrm{m}^{-1}$.

\subsubsection{Viscosity}

The viscosities of solutions were measured using an Ubbelohde suspended level capillary viscometer. The viscometer was suspended vertically in a thermostat at $\pm 0.1{ }^{\circ} \mathrm{C}$. A clean and dry viscometer was used for each measurement. The flow time (usually exceeding $170 \mathrm{~s}$ ) of a constant volume of the solution through the capillary was used to calculate the viscosity of the solution.

\subsubsection{Nuclear Magnetic Resonance (NMR)}

The ${ }^{1} \mathrm{H}-\mathrm{NMR}$ spectra were recorded on a Bruker DMX Avance 600 spectrometer (Osaka, Japan) over a wide temperature range. The sample temperature was kept constant within $\pm 0.1^{\circ} \mathrm{C}$ by using a 
Bruker BCU-05 temperature control unit. The samples were equilibrated at the desired temperature for at least $15 \mathrm{~min}$ prior to measurement.

\subsubsection{High-Sensitivity Differential Scanning Calorimetry (HSDSC)}

Calorimetric measurements were carried out using a Microcal MC-2 instrument (Microcal Inc., Amherst, MA, USA) and the DA-2 dedicated software package (provided by Microcal, Malvern, UK) for data acquisition. Samples were equilibrated in the HSDSC cells for a minimum of 60 min prior to each run, and scans performed at a scan rate of $60 \mathrm{Kh}^{-1}$.

\subsubsection{Dynamic Light Scattering (DLS)}

Dynamic light scattering (DLS) was used to determine the apparent hydrodynamic diameter $\left(D_{h}\right)$ of the micelles. DLS measurements were carried out at $90^{\circ}$ scattering angle on solutions using Autosizer 4800 (Malvern Instruments, Worcestershire, UK) equipped with 192 channel digital correlator (7132) and coherent (Innova, Santa Clara, CA, USA) Ar-ion laser at a wavelength of $514.5 \mathrm{~nm}$. The average diffusion coefficients and hence the hydrodynamic size was obtained by the method of cumulants.

\subsubsection{Small Angle Neutron Scattering (SANS)}

The SANS experiments were performed using a SANS diffractometer at the Dhruva reactor, Bhabha atomic research centre, Trombay. For SANS, copolymer solutions in $\mathrm{D}_{2} \mathrm{O}$ at different concentrations and temperatures were measured. The solutions were held in a quartz cell of $5 \mathrm{~mm}$ thickness with tight-fitting Teflon stoppers. The data were recorded in the Q range of $0.017-0.35 \AA$. All the measured SANS distributions were corrected for the background and solvent contributions. The data were normalized to the cross-sectional unit using standard procedures [50].

The copolymer micelles consist of a hydrophobic core of PPO surrounded by a hydrated shell of PEO. There is very good contrast between the hydrophobic core and the solvent. However, because of a large amount of $\mathrm{D}_{2} \mathrm{O}$ (water of hydration) being present in the outer PEO corona, the scattering contrast between the hydrated corona and the solvent is expected to be poor. In view of this, we assume that the form factor $F(Q)$ depends only on the hydrophobic core radius. The structure factor $\mathrm{S}(\mathrm{Q})$ of the spherical micelles in Equation (1) is calculated using the Percus-Yevick approximation for the case of hard sphere potential in the Ornstein-Zernike equation [51]:

$$
\frac{\mathrm{d} \Sigma}{\mathrm{d} \Omega}(Q)=\mathrm{n} V^{2}\left(\rho_{P}-\rho_{S}\right)^{2} P(Q) S(Q)+B
$$

The mean core radius $\left(R_{\mathrm{c}}\right)$, hard sphere radius $\left(R_{\mathrm{hs}}\right)$ and volume fraction $(\Phi)$ of the micelles have been determined as the fitting parameters from the analysis. The aggregation number is calculated by the relation $N=4 \pi \mathrm{a}^{3} / 3 \mathrm{v}$, where $\mathrm{v}$ is the volume of the surfactant monomer.

\subsubsection{Solubilization}

Drug/dye solubilization measurements were carried out on Shimadzu (UV-2450) UV-Visible double beam spectrophotometers (Tokyo, Japan) with a matched pair of stoppered fused silica cells of $1 \mathrm{~cm}$ optical path length. Saturated drug/dye loaded solutions were prepared in glass vessels by mixing excess powdered drug/dye with copolymer solution and stirring at constant temperature at $200 \mathrm{rpm}$ for 2 days. The solutions were filtered (Millipore, $0.45 \mu \mathrm{m}$ ) to remove insolubilized drug/dye. Blank experiments, without copolymer, were done to determine the solubility of the drug/dye in water. The amount of drug/dye solubilized was determined by measuring absorbance at 255/262/470 nm. Calibration with dilute solutions of the drug/dye dissolved in methanol gave satisfactory Beer-Lambert plots. In a solubilization experiment, the filtered solution was diluted thirty times with methanol, the amount of water after dilution being low enough to allow direct use of the calibration plot. 


\subsubsection{In Vitro Release Studies}

The in vitro release of the poorly water soluble anticancer drugs, quercetin and curcumin, from the micelles was investigated using a pre swelled dialysis bag $\left(M_{\mathrm{W}}\right.$ cut-off $\left.12,000-14,000 \mathrm{Da}\right)$. In brief, $10 \mathrm{~mL}$ of the drug formulations containing approximately $5 \mathrm{mgs}$ of drugs was transferred into respective dialysis bags and immersed into $100 \mathrm{~mL}$ of phosphate buffer saline (PBS), which was placed in a shaking water bath at $37^{\circ} \mathrm{C}$. In addition, $3 \mathrm{~mL}$ sample aliquots were taken from the release medium at scheduled time intervals and the same volume of fresh buffer was refilled to maintain the volume. The concentration of drugs released into PBS was quantified based on their absorbance at $470 \mathrm{~nm}\left(\lambda_{\max }\right.$ for orange OT), $255 \mathrm{~nm}$ ( $\lambda_{\max }$ for quercetin) and $262 \mathrm{~nm}$ ( $\lambda_{\max }$ for curcumin), respectively using a Shimadzu 160 spectrophotometer on a UV-Vis curve, to further conclude the rate of drug release.

\subsubsection{In Vitro Cytotoxicity Assays}

Cytotoxicity of free quercetin and curcumin and their loaded micelles of T904 were assessed on the viability of $\mathrm{CHO}-\mathrm{K} 1$ cells by the 3-(4,5-Dimethylthiazol-2-yl)-2,5-Diphenyltetrazolium Bromide (MTT) assay. These CHO-K1 cells in a logarithmic phase (104 cells/well) were seeded in 96-well plates along with variable concentration of free quercetin and curcumin $(0,12.5,25,50$ and $100 \mu \mathrm{g} / \mathrm{mL})$. The cells were also treated with their equivalent doses loaded in T904 micelles. Incubate these cells for $24 \mathrm{~h}$ in carbon dioxide incubator $\left(5 \% \mathrm{CO}_{2} ; 37^{\circ} \mathrm{C}\right)$. Afterwards, add the MTT solution $(10 \mu \mathrm{L} ; 2.5 \mathrm{mg} / \mathrm{mL})$ into a 96-well plate after centrifuging $(2000 \mathrm{rpm} ; 5 \mathrm{~min}$ ) and dissolved in an equal volume of media. Again, incubate the plate for another $4 \mathrm{~h}$. Finally, the intracellular formazan crystals were settled at the bottom and the supernatant was discarded (again after centrifuging as mentioned above). These crystals were dissolved in dimethyl sulphoxide and its relative growth inhibition was compared with control cells and its optical density was measured at $570 \mathrm{~nm}$. All experiments were set up in triplicates and repeated thrice for statistical analysis. Results were expressed as mean \pm S.E.

The percentage growth inhibition was calculated using the following formula:

$$
\% \text { Growth Inhibition }=\frac{100-(\text { Mean absorbance of individual test })}{(\text { Mean absorbance of Control })} \times 100 .
$$

The half maximal inhibitory concentration $\left(\mathrm{IC}_{50}\right)$ was estimated using the concentration-response and was expressed in the unit $\mu \mathrm{g} / \mathrm{mL}$. The concentration of the test drug required for the inhibition of cell growth by $50 \%$ (CTC50) was generated by the dose-response curves for each cell line.

Statistical Analysis: Data analysis was carried out by two-way ANOVA (SPSS 10.0, SPSS Inc., Chicago, IL, USA). A $p$-value $\leq 0.05$ was contemplated as statistically important.

\section{Results}

\subsection{Characterization of Tetronics ${ }^{\circledR}$ Micelles and the Effect of Salt}

\subsubsection{Cloud Point}

The cloud points (CPs) of all the three copolymers were measured as a function of salt concentration and $\mathrm{pH}$ and are presented in Figure 2. It has been established from the previous studies in literature that copolymers fabricated with longer PEO blocks usually exhibit more hydrophilic character and undergo micellization at elevated temperatures. The occurrence of longer PEO blocks improves the solubility of the copolymer chains in water. Hence, these exhibit higher phase separation temperatures. Conversely, those with shorter PEO blocks ( $>30 \%)$ usually display poor solubility and undergo micellization at comparatively lower temperatures and experiences phase separation at relatively lower temperatures [16,44]. In the present case, as displayed in Table 1, T908 with 80\% $\mathrm{PEO}$ in its constitution remains highly hydrophilic and usually displays $\mathrm{CP}$ at temperatures $>100$ ${ }^{\circ} \mathrm{C}$ in water and, as anticipated, T904 with moderate hydrophilicity with $40 \%$ EO in its constitution undergoes phase separation at temperature $\sim 73{ }^{\circ} \mathrm{C}$. Surprisingly, in the case of T304, despite having 
$40 \%$ EO in its constitution like T904, due to low molecular weight of the constituting PPO block, does not form micelles but remains as unimers even at higher temperatures (discussed in later sections) and undergoes phase separation at a temperature very close to that of T904.

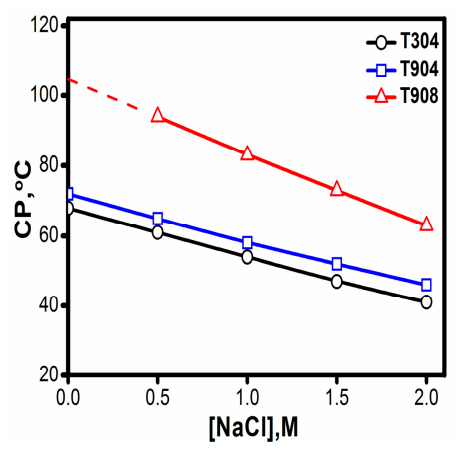

(a)

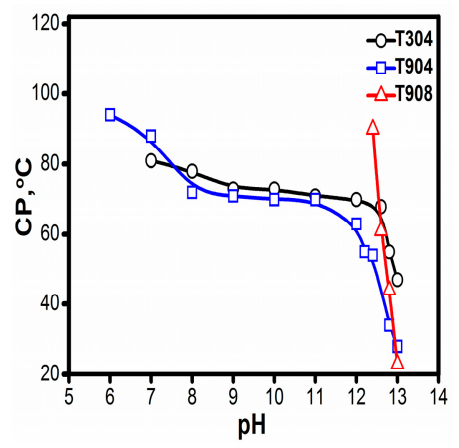

(b)

Figure 2. CP of $5 \%$ Tetronics ${ }^{\circledR}$ (a) as a function of salt concentration and (b) $\mathrm{pH}$.

For all the copolymers, as shown in Figure 2a, there was almost a linear decrease in $\mathrm{CP}$ with an increasing concentration of salt. The presence of salt induces hydrophobicity in the copolymer and makes it prone to form micelles, or micellar growth accounts for the copolymers existing as micelles due to the well-known salting out action of $\mathrm{NaCl}$. A similar $\mathrm{CP}$ depressant role of salt has been observed earlier for Pluronics ${ }^{\circledR}$ and other water soluble uncharged polymers that show lower critical solution behavior [52-55]. Bahadur and coworkers [46,48,49,56] have also reported a similar effect of salt on Tetronics ${ }^{\circledR}$ micelles.

The effect of $\mathrm{pH}$ was also examined for these copolymers as shown in Figure $2 \mathrm{~b}$. The $\mathrm{pH}$ values for the solution were adjusted in the range of 6-13 using $\mathrm{HCl} / \mathrm{NaOH}$ solutions. For T304 and T904, there is only a slight decrease in $\mathrm{CP}$ upon changing $\mathrm{pH}$ in the range 6-10; however, a steep fall is seen above $\mathrm{pH} 10$. The $\mathrm{CPs}$ were higher in acidic $\mathrm{pH}$ because acidic $\mathrm{pH}$ makes the amino groups protonated and thus induces a more hydrophilic character and increases CP. For T908, CPs were measured only in the alkaline $\mathrm{pH}$ (since its $\mathrm{CP}$ in the absence of additives remains $>100{ }^{\circ} \mathrm{C}$ ) where low values of $\mathrm{CP}$ were observed. The decrease in $\mathrm{CP}$ at higher $\mathrm{pH}$ is due to the fact that ethylenediamine group gets completely neutralized at this $\mathrm{pH}$ and thus induces more hydrophobicity in the copolymer units promoting micelle formation, which consequently lowers the $\mathrm{CP}$ values.

\subsubsection{Surface Tension}

In order to study the surface activity of these copolymers at the water/air interface and to determine the CMC values, surface tension measurements were carried out as a function of the copolymer concentration in aqueous medium and also in salt solutions in the case of T908.

Surface tension $\rightarrow \log$ copolymer concentration plots for the three Tetronics ${ }^{\circledR}$ are shown in Figure 3a. T304 owing to its low molecular weight was least surface active and did not show micelle formation at all the concentrations, as also confirmed through SANS, though a progressive decrease in surface tension (upto $10 \% w / v$ ) is observed. On the contrary, Gonzalez-Lopez et al. [20] determined the CMC of T304 in acidic media and observed micelle formation at higher concentrations. T908 with more hydrophilic character was less surface active and showed two break points commonly observed for copolymers with more hydrophilic character. Although improved surface activity and a significant decrease in CMC can be made evident in the presence of salt (Figure 3b). The improved hydrophobicity in the presence of salt is further demonstrated by a single break point (Figure 3b) analogous to moderately hydrophilic copolymers. Conversely, T904 with moderately hydrophilic character displayed highest surface activity among the three copolymers and showed a behavior 
similar to surfactants. Thus, this leads us to a conclusion that, for all of the copolymers, surface activity increased with the increase in molecular weight, decrease in \%EO and in the presence of salt.

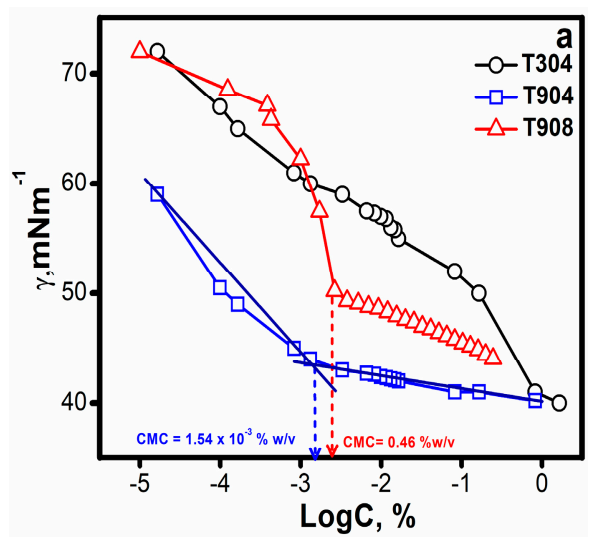

(a)

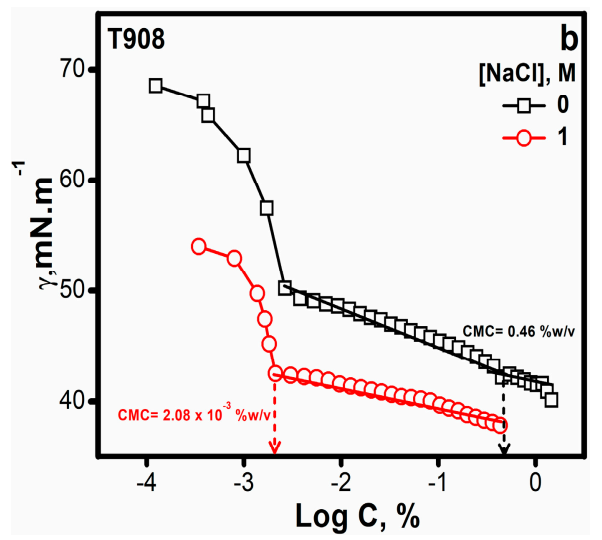

(b)

Figure 3. Surface tension plots (a) for the aqueous solutions of different Tetronics ${ }^{\circledR}$ and (b) T908 solutions in the presence and absence of $1 \mathrm{M}$ salt at $25^{\circ} \mathrm{C}$.

\subsubsection{Nuclear Magnetic Resonance (NMR)}

${ }^{1} \mathrm{H}$ NMR spectra for the three copolymers were recorded at different temperature intervals and the signals for methylene protons of PEO, methylene and methyl protons of PPO were considered to analyze the spectra (Only spectra for T908 has been included). As evident from Figure 4a, a triplet at $1.16 \mathrm{ppm}$ is assigned to the methyl protons of the PPO, broad peaks around 3.65 to $3.45 \mathrm{ppm}$ correspond to the methylene protons of PPO and intense resonance peak at $3.7 \mathrm{ppm}$ correspond to the methylene protons of PEO. As evident in Figure $4 \mathrm{~b}$, an increase in temperature shifts the resonance peaks corresponding to methyl and methylene protons of PPO towards low frequencies with a simultaneous line-width broadening indicating reduced mobility of PPO segments since it forms a hydrophobic core of the micelles.

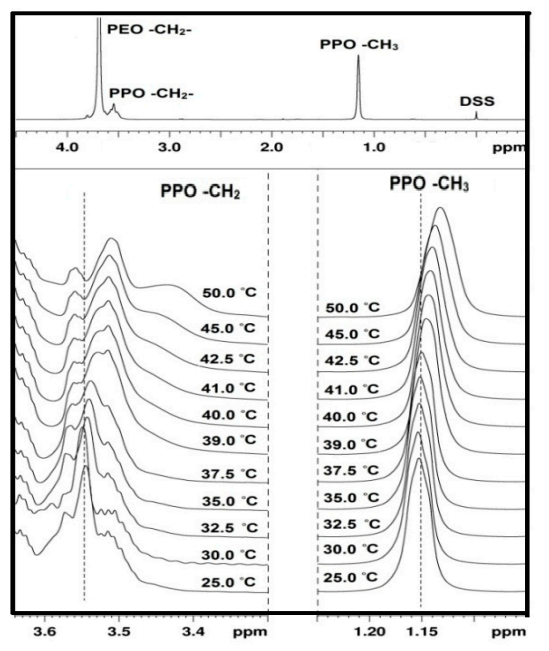

(a) (b)

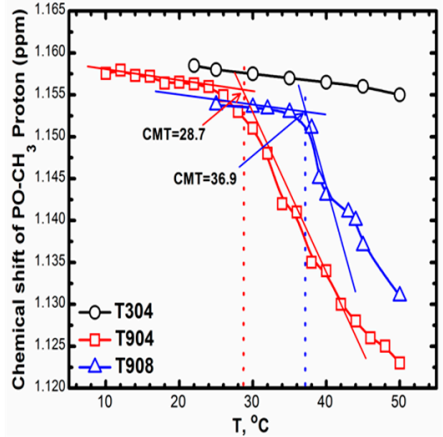

(d)

Figure 4. (a) ${ }^{1} \mathrm{H}-\mathrm{NMR}$ spectra of $10 \%$ T908 in $\mathrm{D}_{2} \mathrm{O}$ at $25^{\circ} \mathrm{C}$; (b) $-\mathrm{CH}_{2}$ - signals of PPO; (c) $-\mathrm{CH}_{3}$ signals of PPO; (d) chemical shift vs. temperature.

The chemical shift observed for the $\mathrm{PPO}-\mathrm{CH}_{3}$ peaks were then plotted against temperature as shown in Figure $4 \mathrm{c}$ to determine the critical micelle concentration (CMT) of block copolymers. The 
CMTs were taken as the inflexion point in the plot. T304 owing to its low molecular weight did not form micelle under the conditions studied despite containing 40\% PEO while T904 (with similar \%PEO) remains much lower than $\mathrm{T} 908$ at the same concentration due to its moderately hydrophobic character. It is interesting to note that T904 and T908 have similar molecular weight of PPO but vary in \%PEO, which sufficiently alters their hydrophobicity and micellar and micellization characteristics. A similar trend is also observed for the hydrophilic linear block copolymers, Pluronics ${ }^{\circledR}[57,58]$.

\subsubsection{HSDSC}

In this study, HSDSC experiments were performed to determine the effect of salt on the CMT of T908. Owing to its hydrophilic character, T908 forms micelles at elevated temperatures as observed in the previous section. Since no micellization was observed in the previous sections for T304, CMT of T304 was not determined. Likewise, measurements for T904, which usually form micelles at lower temperatures, were not carried out since the addition of salt will further decrease the CMT and the practical limitations of the instrument may not allow us to go to such lower temperatures. Hence, the measurements were limited only to T908 to understand the influence of salt on copolymer micelles.

Typical HSDSC thermograms (not shown) with the endothermic peak were obtained signifying the endothermic phase transition from a fully solvated solution of unimers to a solution consisting of solvated micelles with a poly(propylene oxide) microphase inner core. Generally, CMT of the copolymer can be defined by three different methods viz. $T_{\text {onset, }} T_{\text {inf }}$ and $T_{\mathrm{m}}$. All three of the methods were explained in detail in our previous reports [44,47]. In the present study, $T_{\mathrm{m}}$ is chosen as the CMT of the block copolymer.

As evident in data presented in Table 2, the CMT of aqueous solutions of 5\% T908 decreases in the presence of salt. This is attributed to the fact that addition of salt leads to the dehydration of the EO and PO blocks, which favors micellization and thus reduces CMT significantly. Alexandridis and Holzwarth [52] using DSC scrutinized the effect of different salts on the CMT of Pluronics ${ }^{\circledR}$ solutions and observed similar results. Similarly, Bahadur et al. [56] using fluorescence witnessed a similar decrease in CMT of T1307 solutions in the presence of salt.

Table 2. Thermodynamic parameters for micellization of 5\% T908 from high sensitivity differential scanning calorimetry thermograms.

\begin{tabular}{ccccccc}
\hline$[\mathrm{NaCl}], \mathbf{M}$ & $\boldsymbol{T}_{\text {onset }}\left({ }^{\circ} \mathrm{C}\right)$ & $\boldsymbol{T}_{\text {inf }}\left({ }^{\circ} \mathrm{C}\right)$ & $\boldsymbol{T}_{\mathbf{m}}\left({ }^{\circ} \mathrm{C}\right)$ & $\boldsymbol{\Delta H}(\mathbf{k J} / \mathbf{m o l})$ & $\Delta G(\mathbf{k J} / \mathbf{m o l})$ & $\Delta \boldsymbol{S}(\mathbf{k J} / \mathbf{m o l} \cdot \mathrm{K})$ \\
\hline $\mathbf{0}$ & 32.00 & 32.06 & 37.82 & 133.38 & -26.31 & 0.51 \\
$\mathbf{1}$ & 19.03 & 19.73 & 24.83 & 178.45 & -25.25 & 0.68 \\
$\mathbf{2}$ & $\mathrm{a}$ & $\mathrm{a}$ & 20.26 & $\mathrm{a}$ & -24.80 & $\mathrm{a}$ \\
\hline
\end{tabular}

${ }^{\text {a }}$ The pre-transitional baseline was so short to calculate the $T_{\text {onset, }} T_{\text {inf }}$, and $\Delta H$ properly.

\subsubsection{Viscosity}

Viscosities of $10 \% w / v$ solutions of Tetronics ${ }^{\circledR}$ in $\mathrm{H}_{2} \mathrm{O}, 1$ and $2 \mathrm{M} \mathrm{NaCl}$ were measured at different temperatures and the relative viscosities were plotted against temperature as shown in Figure 5.

The viscosity behavior of copolymers was different. For copolymer T304, due to its low molecular weight, there was no effect on viscosity and it remained almost constant at different temperatures. The viscosity did not change even in the presence of salt up to its CP. This is because T304 remains molecularly dissolved and does not show any micelles even at elevated temperatures or in the presence of salt. Conversely, T904 with moderately hydrophilic character occurs as micelles at ambient temperature. Any increase in temperature promotes micellar growth due to increased dehydration of $\mathrm{EO}$ and $\mathrm{PO}$ chains. Hence, more and more unimers participate in micelle formation, eventually leading to micellar growth. Quite interestingly, T908, due to its characteristic hydrophilic character, forms micelles only at high temperature and in the presence of salt. Accordingly, for various concentrations of salts, different morphologies are assumed by the copolymer molecules. In line with this, the 
contribution from the unimers and micelles shows different viscosity behavior. As evident in the figure, with the increase in temperature, the relative viscosity increases initially but decreases at higher temperatures. This is attributed to the fact that increase in temperature leads to the formation of spherical micelles from the existing unimolecular form of copolymer, which, as a result, enhances the viscosity significantly until a maxima is reached at $\sim 55^{\circ} \mathrm{C}$. As the temperature is raised further, the dehydration of EO blocks is triggered and more compact micelles are formed, which eventually decreases the viscosity of the solution. The presence of salt promotes micellization as also reported in the earlier sections. Hence, the maxima shift to lower temperatures in the presence of 1 and $2 \mathrm{M} \mathrm{NaCl}$. A similar trend has been reported in literature for hydrophilic copolymers earlier. Thus, the results are in line with literature.

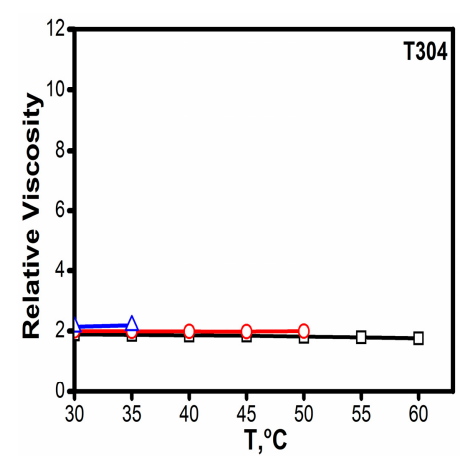

(a)

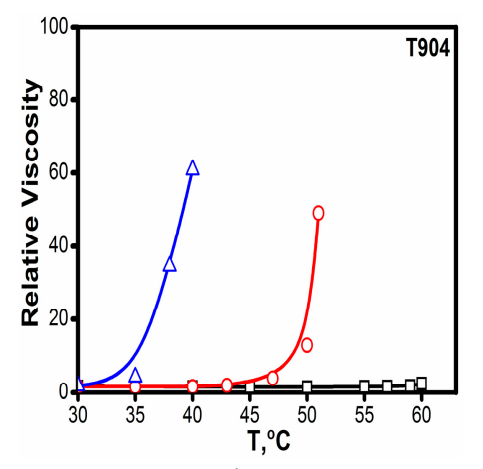

(b)

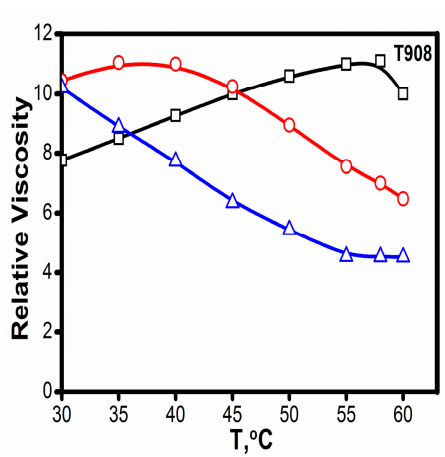

(c)

Figure 5. Effect of temperature on different Tetronic ${ }^{\circledR}$ solutions $(10 \% w / v)$ in the presence of salt ( $\square) 0 \mathrm{M},(\mathrm{O}) 1 \mathrm{M}$ and $(\triangle) 2 \mathrm{M} \mathrm{NaCl}$. (a) relative viscosity of 10\% T304 aqueous and salt solutions versus temperature (b) relative viscosity of 10\% T904 aqueous and salt solutions versus temperature (c) relative viscosity of $10 \%$ T908 aqueous and salt solutions versus temperature.

\subsubsection{DLS}

The apparent hydrodynamic diameter of micelles at different temperatures for $10 \% w / v$ Tetronic ${ }^{\circledR}$ aqueous and salt solutions was determined using DLS as shown in Figure 6. This figure also displays the effect of temperature $\left(30-50{ }^{\circ} \mathrm{C}\right)$ on the above said copolymer solutions in the presence and absence of salt.

T304 unimer peaks of the size $2-5 \mathrm{~nm}$ along with large particles of a few hundred $\mathrm{nm}$ are seen. This simply reflects the presence of molecularly dissolved T304 at all temperature and salt concentrations. In the case of T908, the presence of unimers (5-8 nm) along with another peak originating from the presence of micelles and large particles can be clearly seen. With the increase in temperature or in the presence of salt micellar peaks gets sharper while the contribution from large clusters and unimers decreases. Micelles of size $\sim 15-20 \mathrm{~nm}$ are the predominant species at higher temperatures and in salt solutions. Single peak arising from the micelles (of $\sim 12-20 \mathrm{~nm}$ size) can be seen for moderately hydrophilic T904 at relatively lower temperatures and in the absence of salt. However, micellar growth is observed at elevated temperatures and in the presence of salt. The increased micellar dimensions consequently slow their diffusion in solution, which eventually leads to enhanced solution viscosity.

\subsubsection{SANS}

SANS curves for all three Tetronics ${ }^{\circledR}$ at different temperature are shown in Figure 7 . As evident from Figure $7 \mathrm{a}$, the scattering intensity increases with temperature, though overall remains low for T304, indicating an absence of aggregates and the occurrence of only unimers in the solution. This is attributed to the fact that T304, due to its low molecular weight, is incorporated with shorter PPO blocks and hence cannot form micelles. Likewise, T908 with more hydrophilic character occurs as unimers at $30^{\circ} \mathrm{C}$. However, as the temperature is raised, the overall solubility of the copolymer chain 
decreases, which, in turn, promotes micellization. Thus, as evident in Figure 7c, the scattering intensity of T908 increases significantly as the temperature is raised from 30 to $60^{\circ} \mathrm{C}$. For T904, core-shell micelles were the species present, which show growth at a higher temperature as well as in the presence of salt. It can be observed from Figure $7 \mathrm{~b}$ that the scattering intensity increases significantly with the increase in temperature, clearly indicating micellar growth.

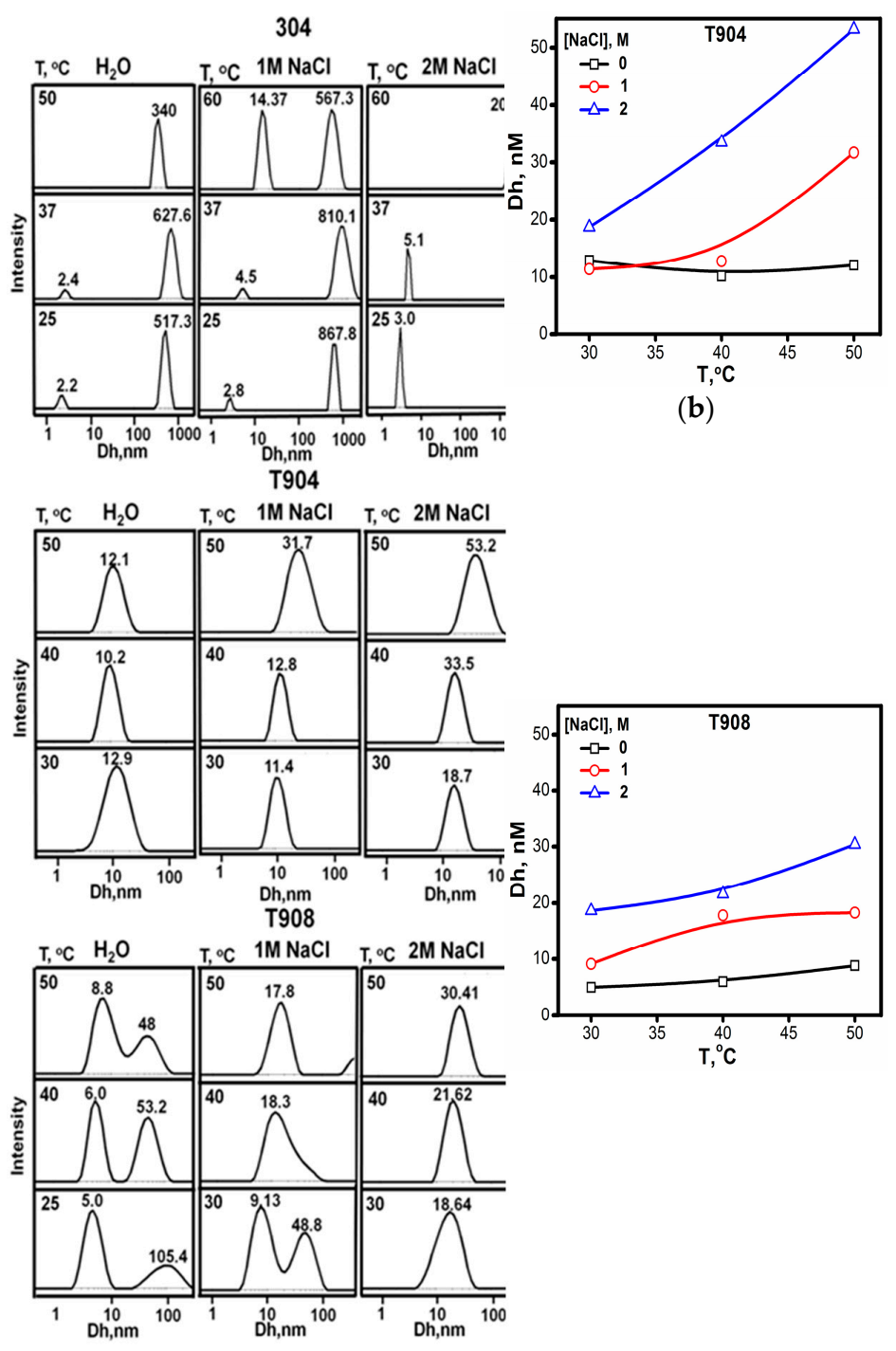

(a)

(c)

Figure 6. Apparent hydrodynamic diameter of different Tetronics ${ }^{\circledR}$ in aqueous and salt solutions. (a) DLS stacks of T304, T904 and T908 in aqueous and salt solutions (b) apparent hydrodynamic diameters of aqueous and salt solutions of T904 as a function of temperature (c) apparent hydrodynamic diameters of aqueous and salt solutions of T908 as a function of temperature.

A similar trend for all three Tetronics ${ }^{\circledR}$ can also be observed from the data presented in Table. In case of T304, it can be understood from the data that neither increase in temperature (Figure 7a) or concentration (Figure 7d) can induce micelle formation and it remains as unimers for all the concentrations and temperatures measured, while, for T904 with moderate hydrophobicity, core-shell micelles with $\mathrm{N}_{\text {agg }} \sim 10$ occur in solution at ambient temperature and, with an increase in temperature, $R_{c}, R_{h s}$ and $N_{a g g}$ increase significantly, clearly indicating micellar growth. In the case of T908, with a more hydrophilic character, only unimers occur at lower temperatures. However, as the temperature is 
raised, micelles with $\mathrm{N}_{\mathrm{agg}} \sim 7$ are formed at $40{ }^{\circ} \mathrm{C}$ and an increase in micellar parameters is observed at still higher temperatures, clearly indicating micellar growth at higher temperatures.

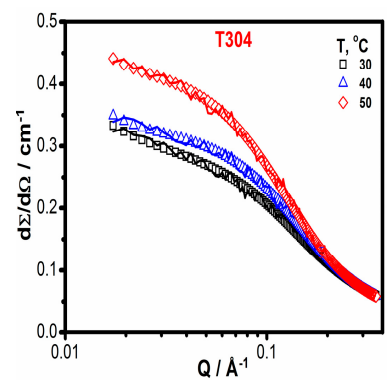

(a)

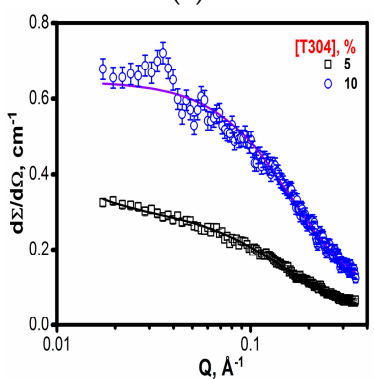

(d)

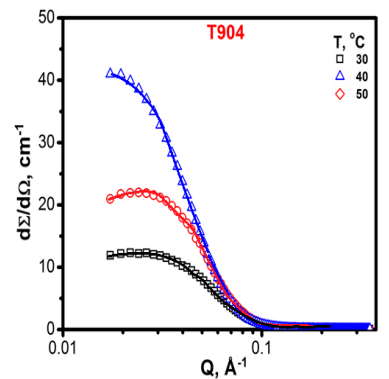

(b)

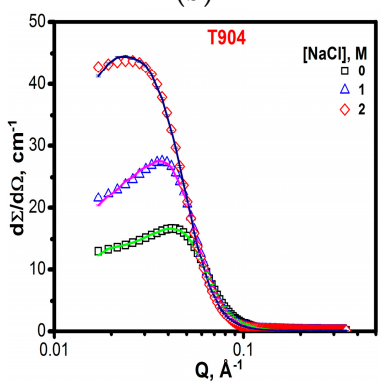

(e)

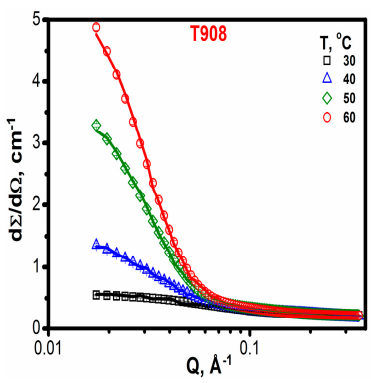

(c)

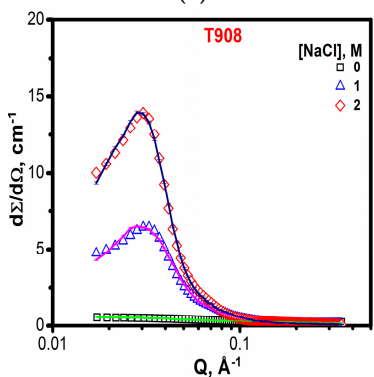

$(\mathbf{f})$

Figure 7. Small angle neutron scattering curves (a) for 10\% T304 as a function of temperature (b) for $5 \% \mathrm{~T} 904$ as a function of temperature (c) for $10 \%$ T908 as a function of temperature (d) for $5 \%$ and $10 \%$ T304 aqueous solutions (e) for 10\% T904 aqueous as a function of salt concentration and (f) for $10 \%$ T908 aqueous solutions as a function of salt concentration.

The presence of salt has a similar effect and leads to micellar growth at low temperatures. As evident in Figure $7 \mathrm{e}, \mathrm{f}$, the increase in concentration of salt improves the scattering intensity indicating growth in micelles. This can be further seen from the calculated parameters shown in Table 3. Thus, SANS results indicate micellar growth in copolymer solutions (except T304) with the increase in temperature/salt concentration in line with the results attained by other techniques.

Table 3. Micellar parameters of $10 \%$ Tetronics $^{\circledR}$ in $\mathrm{D}_{2} \mathrm{O}$ obtained from small angle neutron scattering analysis.

\begin{tabular}{|c|c|c|c|c|c|c|}
\hline Tetronic $^{\circledR}$ & {$[\mathrm{NaCl}], \mathrm{M}$} & Temperature, ${ }^{\circ} \mathrm{C}$ & $\mathbf{R}_{\mathrm{c}}, \AA$ & $\mathbf{R}_{\mathrm{hs}}, \AA$ & $\mathbf{R}_{\mathrm{g}}, \AA$ & $\mathrm{N}_{\text {agg }}$ \\
\hline $5 \%$ T304 & 0 & 30 & - & - & 10.6 & - \\
\hline 10\% Т304 & 0 & 30 & - & - & 11.8 & - \\
\hline 10\% Т304 & 0 & 35 & - & - & 11.1 & - \\
\hline $10 \%$ T304 & 0 & 50 & - & - & 13.0 & - \\
\hline 10\% T908 & 0 & 30 & - & - & 25.8 & - \\
\hline 10\% T908 & 0 & 40 & 39.9 & - & - & 7 \\
\hline 10\% T908 & 0 & 50 & 57.2 & - & - & 10 \\
\hline 10\% T908 & 0 & 60 & 60.1 & - & - & 13 \\
\hline $5 \%$ T904* & 0 & 30 & 25.0 & 52.2 & - & 10 \\
\hline 5\% T904* & 0 & 40 & 29.9 & 52.2 & - & 18 \\
\hline $5 \%$ T904* & 0 & 50 & 33.0 & 129.0 & - & 23 \\
\hline 10\% T904 & 0 & 30 & 34.7 & 51.6 & - & 24 \\
\hline 10\% T904 & $1 \mathrm{M}$ & 30 & 39.9 & 59.6 & - & 36 \\
\hline 10\% T904 & $2 \mathrm{M}$ & 30 & 43.61 & 65.7 & - & 47 \\
\hline $10 \%$ T908 & $1 \mathrm{M}$ & 30 & 25.36 & 81.6 & - & 8 \\
\hline $10 \%$ T908 & $2 \mathrm{M}$ & 30 & 44.3 & 84.9 & - & 43 \\
\hline
\end{tabular}

* From our previous report [29]. 


\subsubsection{Micellar Solubilization}

To investigate the solubilization behavior of micelles from different Tetronics ${ }^{\circledR}$ in water and salt solutions, one model of hydrophobic dye Orange OT and two drugs-quercetin and curcumin-were taken. As evident in Figure 8, the solubility of the dye increased in the presence of salt. However, for T304, the solubility of the dye was negligible and did not improve in the presence of salt. In contrast, T908 showed poor solubility of dye in the absence of salt, but the solubility marginally increased with the progressive addition of salt. The maximum solubility of the dye was observed for T904 solutions, which further increased many folds in the presence of salt.

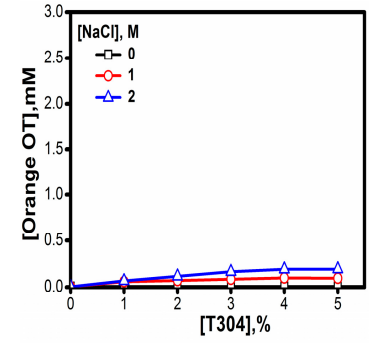

(a)

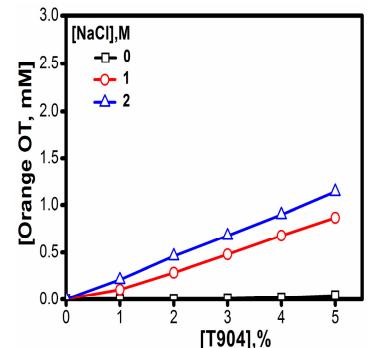

(b)

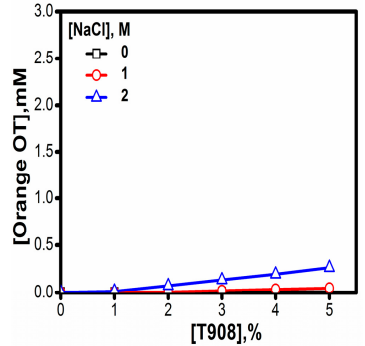

(c)

Figure 8. Orange OT Solubility in (a) 10\% T304 (b) 10\% T904 and (c) 10\% T908 aqueous and salt solutions ( $\square) 0 \mathrm{M},(\mathrm{O}) 1 \mathrm{M}$ and $(\triangle) 2 \mathrm{M} \mathrm{NaCl}$ at $30^{\circ} \mathrm{C}$.

A similar solubilizing trend of the copolymers was noted for the two poorly water soluble anti-cancer drugs viz. quercetin and curcumin as presented in Figure 9. Pillai et al. [43] compared the solubilizing behavior of the two copolymers T1304 and T1307 in the presence of glycine and observed many fold increase in the solubility of quercetin. The presence of glycine in the above case has an analogous effect to that of salt in the present study. A similar trend in the presence of salt has also been observed by Parekh et al. [59] for the solubility of nimesulide drug by T904 micelles at different copolymer concentrations.

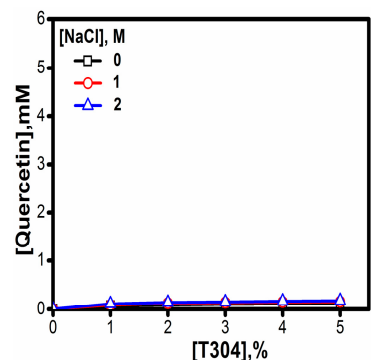

(a)

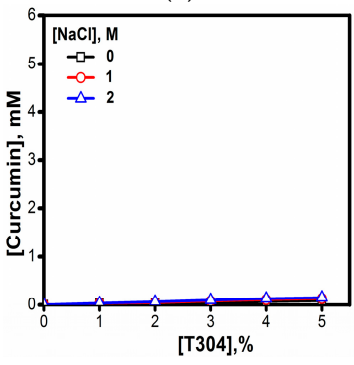

(d)

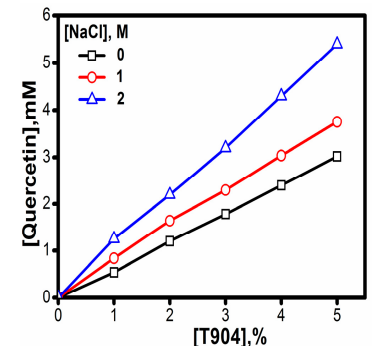

(b)

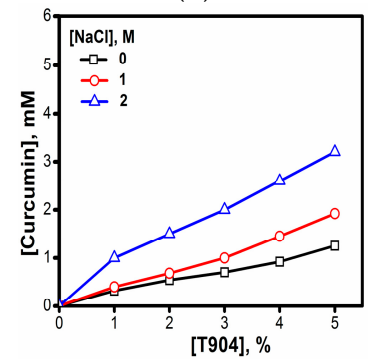

(e)

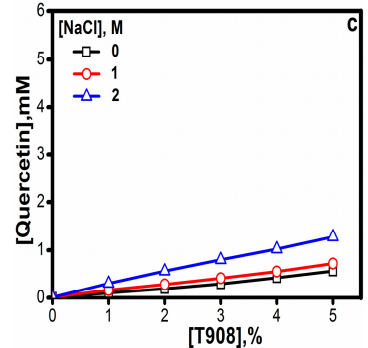

(c)

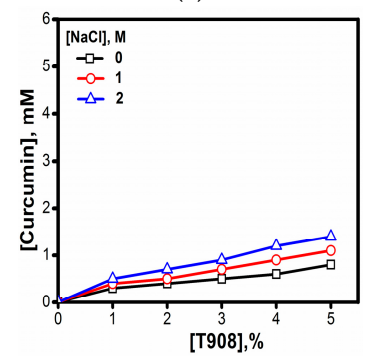

(f)

Figure 9. Solubility of quercetin $(\mathbf{a}-\mathbf{c})$ and curcumin $(\mathbf{d}-\mathbf{f})$ in Tetronic ${ }^{\circledR}$ solutions in the presence of $(\square)$ $0 \mathrm{M},(\mathrm{O}) 1 \mathrm{M}$ and $(\triangle) 2 \mathrm{M} \mathrm{NaCl}$ at $30^{\circ} \mathrm{C}$. 


\subsubsection{In Vitro Drug Release}

In recent years, nanocarrier delivery systems have gained enormous attention for targeting anti-cancer drugs to tumors [60]. Micelles of natural and synthetic biocompatible polymers have been extensively examined as potential carrier materials for drug delivery [61-63] by virtue of their dimensions in nano range, competence to shield the encapsulated drug, targeting features by means of the enhanced permeability and retention (EPR) effect [64-66], and superior therapeutic capabilities [67]. In addition to their targeting ability, biocompatibility, enhanced circulation time and reduced toxicity are some of the prime factors responsible for the success of these polymers in drug delivery systems. With this approach, in the present work, we have tried to explore the in vitro release behaviors of curcumin and quercetin-loaded T904 micelle formulations under physiological conditions. Since the maximum solubility of the dye and drug in the previous section was observed for the copolymer solutions of T904, the release study was limited only to it.

Figure 10 shows the cumulative release profile of two hydrophobic drugs (quercetin and curcumin) versus time where $2 \%$ T904 was taken as the release media for understanding its role in in vitro release of both the drugs in physiological conditions. The time intervals were chosen by trial and error method and the study of release was restricted only for the initial $50 \%$. The release remains slow and sustained for both drugs and only about $7 \%$ release is observed for curcumin and $18 \%$ of release is observed for quercetin during the early $24 \mathrm{~h}$ and approximately $50 \%$ of curcumin is released in 11 days while for quercetin in about 14 days. This is due to the fact that both the drugs remain localized within the core of the micelle and results in sustained release from this region.

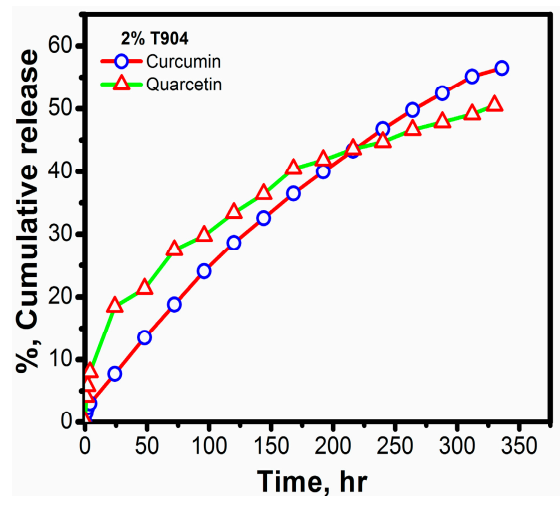

Figure 10. In vitro release profile of $(\triangle)$ quercetin and $(\mathrm{O})$ curcumin from $\mathrm{T} 904$ micelles at physiological conditions ( $\left.\mathrm{pH} 7.4,37^{\circ} \mathrm{C}\right)$.

To understand the drug release kinetics and mechanism, the data was estimated mathematically using zero-order kinetics, first-order kinetics and Higuchi model. The prime condition for choosing the most appropriate model was grounded on best goodness-of-fit ( $R^{2}$ values). The $k_{0}, k_{1}$, and $k_{\mathrm{H}}$ values were estimated by fitting the data into corresponding equations and are given in Table 4 along with the regression coefficients $\left(R^{2}\right)$.

Table 4. Different kinetic models describing the release pattern of the anticancer drugs, curcumin and quercetin, from T904 micelles.

\begin{tabular}{|c|c|c|c|c|c|c|}
\hline \multirow{3}{*}{ Drug } & \multicolumn{6}{|c|}{ Mathematical Models for Drug Release Kinetics } \\
\hline & \multicolumn{2}{|c|}{ Zero Order } & \multicolumn{2}{|c|}{ First Order } & \multicolumn{2}{|l|}{ Higuchi } \\
\hline & $k_{0}\left(\mathrm{M} . \mathrm{h}^{-1}\right)$ & $R^{2}$ & $k_{1}\left(\mathrm{~h}^{-1}\right)$ & $R^{2}$ & $k_{\mathrm{H}}\left(\mathrm{M} \cdot \mathrm{h}^{-1 / 2}\right)$ & $R^{2}$ \\
\hline curcumin & 0.169 & 0.99 & 0.004 & 0.76 & 3.321 & 0.98 \\
\hline quercetin & 0.131 & 0.90 & 0.002 & 0.69 & 2.69 & 0.99 \\
\hline
\end{tabular}


From the results shown in Table 4, it is clearly evident that, for T904 micelles, the release of curcumin follows zero order kinetics while that of quercetin follows Higuchi equation. It has been established in literature that Higuchi and zero order kinetics indicate controlled drug diffusion. Hence, we can come to a conclusion that, from T904 micelles, both the drugs were released through diffusion.

\subsubsection{In Vitro Cytotoxicity}

To investigate the cytotoxicity of curcumin and quercetin from 2\% T904 micelles, IC50 was determined on the CHO-K1 cell lines with different concentrations of curcumin and quercetin was evaluated using MTT assay and the data are presented in Table 5. As portrayed in Figure 11, no obvious decline in cell viability was observed after incubation with the blank micelles, indicating that the copolymer was nontoxic for being used as nanocarriers.

Table 5. The Half Maximal Inhibitory Concentration $\left(\mathrm{IC}_{50}\right)$ of curcumin, quercetin and drug loaded micelles of T904 in the Chinese Hampster Ovarian Cells (CHO-K1 cells).

\begin{tabular}{ccc}
\hline \multirow{2}{*}{ Solvent } & \multicolumn{2}{c}{ IC $_{50}, \boldsymbol{\mu g} / \mathbf{m L}$} \\
\cline { 2 - 3 } & Curcumin & Quercetin \\
\hline $\mathrm{H}_{2} \mathrm{O}$ & 18.60 & 55.2 \\
$\mathrm{~T} 904$ & 45.8 & 48.2 \\
\hline
\end{tabular}

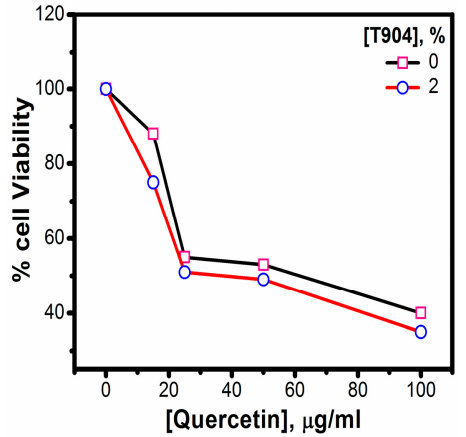

(a)

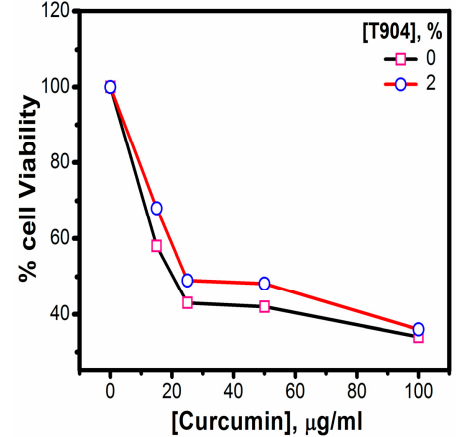

(b)

Figure 11. In vitro cell viability of (a) quercetin and (b) curcumin in the presence and absence of $2 \% \mathrm{~T} 904$.

To evaluate the feasibility of using this copolymer for cancer therapy, we compared the anticancer effects of free curcumin and quercetin with the drug-loaded T904 micelles. From Figure 11a, it is evident that the quercetin loaded micelles displayed more inhibition of proliferation of CHO-K1 cells than free drugs, while, in the case of curcumin, the $\mathrm{IC}_{50}$ of curcumin loaded micelles was comparatively larger than free form. A similar trend has been observed earlier by Pillai et al. [46] for the release of curcumin from the micelles of T1304. According to them, the possible cause for such deviation is due to the difference of drug release rate from micelles inside the cells.

\section{Conclusions}

Aqueous solution behaviour of three star shaped EO-PO block copolymers with different molecular characteristics was examined at different temperature and in the presence of salt using a variety of techniques. The self-assembly was found to be markedly dependent on their molecular characteristics and solution conditions. Data on micellar/phase behavior and interfacial characteristics of the copolymers are reported. More hydrophobic T904 formed micelles at low temperature and showed micellar growth with temperature, T908 with more hydrophilic character does not form micelles at ambient temperature but undergoes micellization at elevated temperatures while T304 
with moderate hydrophobicity but low molecular weight remains molecularly dissolved in water in all of the conditions, and does not form micelles even at higher temperatures or in the presence of salt. The presence of salt has an analogous effect to that observed with the increase in temperature. Viscosity/DLS/SANS suggests growth in T904 micelles with temperature. NMR yields CMT, which decreases in the presence of salt. The solubility of dye and drugs improved in the presence of salt and with the increase in copolymer concentration. The in vitro release profiles for both of the drugs showed a slow and sustained release pattern from T904 micelles, and IC50 values for quercetin decreased significantly while increasing for curcumin, probably due to the slow release rate from the core of micelles. Thus, fine-tuning in micellar parameters using the copolymer of desired molecular characteristics and salt at desired temperatures and $\mathrm{pH}$ may be useful as nanoreservoirs for delivery systems.

Acknowledgments: All of the authors thank V. K. Aswal (BARC, Mumbai, India) for SANS measurements, Junhe Ma (Ashland Inc.) for NMR, Li-Jen Chen (National Taiwan University, Taipei) for HSDSC and Urjita Sheth for release kinetics and toxicity measurements. Pratap Bahadur thanks University Grants Commision, New Delhi (India) for fellowship.

Author Contributions: Pratap Bahadur conceived and designed the experiments; Bijal Vyas performed the experiments; Sadafara A. Pillai analyzed the data and wrote the paper; Anita Bahadur contributed reagents/materials/analysis tools.

Conflicts of Interest: The authors declare no conflict of interest.

\section{References}

1. Nakashima, K.; Bahadur, P. Aggregation of water-soluble block copolymers in aqueous solutions: Recent trends. Adv. Colloid Interface Sci. 2006, 123, 75-96. [CrossRef] [PubMed]

2. Bahadur, P. Block copolymers-their microdomain formation (in solid state) and surfactant behaviour (in solution). Curr. Sci. 2001, 80, 1002-1007.

3. Riess, G. Micellization of block copolymers. Prog. Polym. Sci. 2003, 28, 1107-1170. [CrossRef]

4. Sang, L.-C.; Coppens, M.-O. Effects of surface curvature and surface chemistry on the structure and activity of proteins adsorbed in nanopores. Phys. Chem. Chem. Phys. 2011, 13, 6689-6698. [CrossRef] [PubMed]

5. Chen, J.-K.; Chang, C.-J. Fabrications and applications of stimulus-responsive polymer films and patterns on surfaces: A review. Materials 2014, 7, 805-875. [PubMed]

6. Singh, V.; Khullar, P.; Dave, P.N.; Kaura, A.; Bakshi, M.S.; Kaur, G. PH and thermo-responsive tetronic micelles for the synthesis of gold nanoparticles: Effect of physiochemical aspects of tetronics. Phys. Chem. Chem. Phys. 2014, 16, 4728-4739. [CrossRef] [PubMed]

7. Habas, J.-P.; Pavie, E.; Perreur, C.; Lapp, A.; Peyrelasse, J. Nanostructure in block copolymer solutions: Rheology and small-angle neutron scattering. Phys. Rev. E 2004, 70, 061802. [CrossRef] [PubMed]

8. Fernandez-Tarrio, M.; Yañez, F.; Immesoete, K.; Alvarez-Lorenzo, C.; Concheiro, A. Pluronic and tetronic copolymers with polyglycolyzed oils as self-emulsifying drug delivery systems. AAPS PharmSciTech 2008, 9, 471-479. [CrossRef] [PubMed]

9. Hedberg, E.L.; Shih, C.K.; Solchaga, L.A.; Caplan, A.I.; Mikos, A.G. Controlled release of hyaluronan oligomers from biodegradable polymeric microparticle carriers. J. Control. Release 2004, 100, 257-266. [CrossRef] [PubMed]

10. Oh, K.T.; Bronich, T.K.; Kabanov, A.V. Micellar formulations for drug delivery based on mixtures of hydrophobic and hydrophilic pluronic ${ }^{\circledR}$ block copolymers. J. Control. Release 2004, 94, 411-422. [CrossRef] [PubMed]

11. Sezgin, Z.; Yüksel, N.; Baykara, T. Preparation and characterization of polymeric micelles for solubilization of poorly soluble anticancer drugs. Eur. J. Pharm. Biopharm. 2006, 64, 261-268. [CrossRef] [PubMed]

12. Csaba, N.; Caamaño, P.; Sánchez, A.; Domínguez, F.; Alonso, M.J. Plga: Poloxamer and plga: Poloxamine blend nanoparticles: New carriers for gene delivery. Biomacromolecules 2005, 6, 271-278. [CrossRef] [PubMed]

13. Hamley, I.W. The Physics of Block Copolymers; Oxford University Press: New York, NY, USA, 1998; Volume 19.

14. Alexandridis, P.; Lindman, B. Amphiphilic Block Copolymers: Self-Assembly and Applications; Elsevier: Amsterdam, The Netherlands, 2000. 
15. Zhou, Z.; Chu, B. Anomalous association behavior of an ethylene oxide/propylene oxide aba block copolymer in water. Macromolecules 1987, 20, 3089-3091. [CrossRef]

16. Almgren, M.; Brown, W.; Hvidt, S. Self-aggregation and phase behavior of poly(ethylene oxide)-poly(propylene oxide)-poly(ethylene oxide) block copolymers in aqueous solution. Colloid Polym. Sci. 1995, 273, 2-15. [CrossRef]

17. Liu, T.; Xu, G.; Gong, H.; Pang, J.; He, F. Effect of alcohols on aggregation behaviors of branched block polyether tetronic 1107 at an air/liquid surface. Langmuir 2011, 27, 9253-9260. [CrossRef] [PubMed]

18. Nivaggioli, T.; Tsao, B.; Alexandridis, P.; Hatton, T.A. Microviscosity in pluronic and tetronic poly(ethylene oxide) poly(propylene oxide) block-copolymer micelles. Langmuir 1995, 11, 119-126. [CrossRef]

19. Ganguly, R.; Kadam, Y.; Choudhury, N.; Aswal, V.; Bahadur, P. Growth and interaction of the tetronic 904 micelles in aqueous alkaline solutions. J. Phys. Chem. B 2011, 115, 3425-3433. [CrossRef] [PubMed]

20. Gonzalez-Lopez, J.; Alvarez-Lorenzo, C.; Taboada, P.; Sosnik, A.; Sandez-Macho, I.; Concheiro, A. Self-associative behavior and drug-solubilizing ability of poloxamine (tetronic) block copolymers. Langmuir 2008, 24, 10688-10697. [CrossRef] [PubMed]

21. Goy-López, S.; Taboada, P.; Cambón, A.; Juárez, J.; Alvarez-Lorenzo, C.; Concheiro, A.; Mosquera, V.C. Modulation of size and shape of au nanoparticles using amino-x-shaped poly(ethylene oxide)—Poly(propylene oxide) block copolymers. J. Phys. Chem. B 2009, 114, 66-76. [CrossRef] [PubMed]

22. Dong, J.; Chowdhry, B.Z.; Leharne, S.A. Surface activity of poloxamines at the interfaces between air-water and hexane-water. Colloids Surf. A 2003, 212, 9-17. [CrossRef]

23. Dong, J.; Armstrong, J.; Chowdhry, B.Z.; Leharne, S.A. Thermodynamic modelling of the effect of pH upon aggregation transitions in aqueous solutions of the poloxamine, T701. Thermochim. Acta 2004, 417, 201-206. [CrossRef]

24. Dong, J.; Chowdhry, B.Z.; Leharne, S.A. Solubilisation of polyaromatic hydrocarbons in aqueous solutions of poloxamine t803. Colloids Surf. A 2004, 246, 91-98. [CrossRef]

25. Armstrong, J.K.; Chowdhry, B.Z.; Snowden, M.J.; Dong, J.; Leharne, S.A. The effect of ph and concentration upon aggregation transitions in aqueous solutions of poloxamine T701. Int. J. Pharm. 2001, 229, 57-66. [CrossRef]

26. Tirnaksiz, F.; Kalsin, O. A topical w/o/w multiple emulsions prepared with tetronic 908 as a hydrophilic surfactant: Formulation, characterization and release study. J. Pharm. Pharm. Sci. 2004, 8, 299-315.

27. Fernandez-Tarrio, M.; Alvarez-Lorenzo, C.; Concheiro, A. Calorimetric approach to tetronic/water interactions. J. Therm. Anal. Calorim. 2007, 87, 171-178. [CrossRef]

28. Xin, X.; Xu, G.; Zhang, Z.; Chen, Y.; Wang, F. Aggregation behavior of star-like peo-ppo-peo block copolymer in aqueous solution. Eur. Polym. J. 2007, 43, 3106-3111. [CrossRef]

29. Kadam, Y.; Singh, K.; Marangoni, D.; Ma, J.; Aswal, V.; Bahadur, P. Induced micellization and micellar transitions in aqueous solutions of non-linear block copolymer Tetronic ${ }^{\circledR}$ T904. J. Colloid Interface Sci. 2010, 351, 449-456. [CrossRef] [PubMed]

30. Branca, C.; Magazu, S.; Migliardo, F. Star polymer/water solutions: New experimental findings. Condens. Matter Phys. 2008, 5, 275-284. [CrossRef]

31. Wu, J.; Xu, Y.; Dabros, T.; Hamza, H. Effect of EO and PO positions in nonionic surfactants on surfactant properties and demulsification performance. Colloids Surf. A 2005, 252, 79-85. [CrossRef]

32. Mansur, C.R.; Barboza, S.P.; González, G.; Lucas, E.F. Pluronic $\times$ tetronic polyols: Study of their properties and performance in the destabilization of emulsions formed in the petroleum industry. J. Colloid Interface Sci. 2004, 271, 232-240. [CrossRef] [PubMed]

33. Tonge, S.; Jones, L.; Goodall, S.; Tighe, B. The ex vivo wettability of soft contact lenses. Curr. Eye Res. 2001, 23, 51-59. [CrossRef] [PubMed]

34. Subbaraman, L.N.; Bayer, S.; Gepr, S.; Glasier, M.-A.; Lorentz, H.; Senchyna, M.; Jones, L. Rewetting drops containing surface active agents improve the clinical performance of silicone hydrogel contact lenses. Optom. Vis. Sci. 2006, 83, 143-151. [CrossRef] [PubMed]

35. Cappel, M.J.; Kreuter, J. Effect of nonionic surfactants on transdermal drug delivery: Ii. Poloxamer and poloxamine surfactants. Int. J. Pharm. 1991, 69, 155-167. [CrossRef]

36. Moghimi, S.M.; Hunter, A.C. Poloxamers and poloxamines in nanoparticle engineering and experimental medicine. Trends Biotechnol. 2000, 18, 412-420. [CrossRef] 
37. Sosnik, A.; Sefton, M.V. Poloxamine hydrogels with a quaternary ammonium modification to improve cell attachment. J. Biomed. Mater. Res. Part A 2005, 75, 295-307. [CrossRef] [PubMed]

38. Sosnik, A.; Leung, B.; McGuigan, A.P.; Sefton, M.V. Collagen/poloxamine hydrogels: Cytocompatibility of embedded hepg2 cells and surface-attached endothelial cells. Tissue Eng. 2005, 11, 1807-1816. [CrossRef] [PubMed]

39. De Lisi, R.; Giammona, G.; Lazzara, G.; Milioto, S. Copolymers sensitive to temperature and $\mathrm{pH}$ in water and in water+ oil mixtures: A dsc, itc and volumetric study. J. Colloid Interface Sci. 2011, 354, 749-757. [CrossRef] [PubMed]

40. Larrañeta, E.; Isasi, J.R. Non-covalent hydrogels of cyclodextrins and poloxamines for the controlled release of proteins. Carbohydr. Polym. 2014, 102, 674-681. [CrossRef] [PubMed]

41. González-Gaitano, G.; Müller, C.L.; Radulescu, A.; Dreiss, C.C.A. Modulating the self-assembly of amphiphilic x-shaped block copolymers with cyclodextrins: Structure and mechanisms. Langmuir 2015, 31, 4096-4105. [CrossRef] [PubMed]

42. Poellmann, M.J.; Sosnick, T.R.; Meredith, S.C.; Lee, R.C. The pentablock amphiphilic copolymer T1107 prevents aggregation of denatured and reduced lysozyme. Macromol. Biosci. 2016, 17. [CrossRef] [PubMed]

43. Pillai, S.A.; Bharatiya, B.; Casas, M.; Lage, E.V.; Sandez-Macho, I.; Pal, H.; Bahadur, P. A multitechnique approach on adsorption, self-assembly and quercetin solubilization by Tetronics ${ }^{\circledR}$ micelles in aqueous solutions modulated by glycine. Colloids Surf. B 2016, 148, 411-421. [CrossRef] [PubMed]

44. Pillai, S.A.; Lee, C.-F.; Chen, L.-J.; Aswal, V.K.; Bahadur, P. Glycine elicited self-assembly of amphiphilic star block copolymers with contradistinct hydrophobicities. Colloids Surf. A 2016, 506, 234-244. [CrossRef]

45. Pillai, S.A.; Lee, C.-F.; Ray, D.; Aswal, V.K.; Pal, H.; Chen, L.-J.; Bahadur, P. Microstructure of copolymeric micelles modulated by ionic liquids: Investigating the role of the anion and cation. RSC Adv. 2016, 6, 87299-87313. [CrossRef]

46. Pillai, S.A.; Sheth, U.; Bahadur, A.; Aswal, V.K.; Bahadur, P. Salt induced micellar growth in aqueous solutions of a star block copolymer tetronic ${ }^{\circledR} 1304$ : Investigating the role in solubilizing, release and cytotoxicity of model drugs. J. Mol. Liq. 2016, 224, 303-310. [CrossRef]

47. Pillai, S.A.; Lee, C.-F.; Chen, L.-J.; Bahadur, P.; Aswal, V.K.; Bahadur, P. Thermal and scattering studies of tetronic ${ }^{\circledR} 1304$ micelles in the presence of industrially important glycols, their oligomers, cellosolves, carbitols, ethers and esters. Colloids Surf. A 2016, 506, 576-585. [CrossRef]

48. Patidar, P.; Pillai, S.A.; Sheth, U.; Bahadur, P.; Bahadur, A. Glucose triggered enhanced solubilisation, release and cytotoxicity of poorly water soluble anti-cancer drugs from T1307 micelles. J. Biotechnol. 2017, 254, 43-50. [CrossRef] [PubMed]

49. Patidar, P.; Pillai, S.A.; Bahadur, P.; Bahadur, A. Tuning the self-assembly of EO-PO block copolymers and quercetin solubilization in the presence of some common pharmacuetical excipients: A comparative study on a linear triblock and a starblock copolymer. J. Mol. Liq. 2017, 241, 511-519. [CrossRef]

50. Chen, S.-H.; Lin, T.-L.; Price, D. Methods of Experimental Physics; Academic Press: New York, NY, USA, 1987; Volume 23, p. 489.

51. Percus, J.K.; Yevick, G.J. Analysis of classical statistical mechanics by means of collective coordinates. Phys. Rev. 1958, 110. [CrossRef]

52. Alexandridis, P.; Holzwarth, J.F. Differential scanning calorimetry investigation of the effect of salts on aqueous solution properties of an amphiphilic block copolymer (poloxamer). Langmuir 1997, 13, 6074-6082. [CrossRef]

53. Jain, N.; George, A.; Bahadur, P. Effect of salt on the micellization of pluronic P65 in aqueous solution. Colloids Surf. A 1999, 157, 275-283. [CrossRef]

54. Pandit, N.; Trygstad, T.; Croy, S.; Bohorquez, M.; Koch, C. Effect of salts on the micellization, clouding, and solubilization behavior of pluronic f127 solutions. J. Colloid Interface Sci. 2000, 222, 213-220. [CrossRef] [PubMed]

55. Gu, T.; Galera-Gomez, P. Clouding of triton x-114: The effect of added electrolytes on the cloud point of triton x-114 in the presence of ionic surfactants. Colloids Surf. A 1995, 104, 307-312. [CrossRef]

56. Bahadur, A.; Cabana-Montenegro, S.; Aswal, V.K.; Lage, E.V.; Sandez-Macho, I.; Concheiro, A.; Alvarez-Lorenzo, C.; Bahadur, P. Nacl-triggered self-assembly of hydrophilic poloxamine block copolymers. Int. J. Pharm. 2015, 494, 453-462. [CrossRef] [PubMed] 
57. Alexandridis, P.; Holzwarth, J.F.; Hatton, T.A. Micellization of poly(ethylene oxide)-poly(propylene oxide)-poly(ethylene oxide) triblock copolymers in aqueous solutions: Thermodynamics of copolymer association. Macromolecules 1994, 27, 2414-2425. [CrossRef]

58. Alexandridis, P.; Nivaggioli, T.; Hatton, T.A. Temperature effects on structural properties of pluronic P104 and f108 peo-ppo-peo block copolymer solutions. Langmuir 1995, 11, 1468-1476. [CrossRef]

59. Parekh, P.; Singh, K.; Marangoni, D.; Bahadur, P. Micellization and solubilization of a model hydrophobic drug nimesulide in aqueous salt solutions of tetronic ${ }^{\circledR}$ T904. Colloids Surf. B 2011, 83, 69-77. [CrossRef] [PubMed]

60. Danhier, F.; Feron, O.; Préat, V. To exploit the tumor microenvironment: Passive and active tumor targeting of nanocarriers for anti-cancer drug delivery. J. Control. Release 2010, 148, 135-146. [CrossRef] [PubMed]

61. Tanner, P.; Baumann, P.; Enea, R.; Onaca, O.; Palivan, C.; Meier, W. Polymeric vesicles: From drug carriers to nanoreactors and artificial organelles. Acc. Chem. Res. 2011, 44, 1039-1049. [CrossRef] [PubMed]

62. Kedar, U.; Phutane, P.; Shidhaye, S.; Kadam, V. Advances in polymeric micelles for drug delivery and tumor targeting. Nanomedicine 2010, 6, 714-729. [CrossRef] [PubMed]

63. Elsabahy, M.; Wooley, K.L. Design of polymeric nanoparticles for biomedical delivery applications. Chem. Soc. Rev. 2012, 41, 2545-2561. [CrossRef] [PubMed]

64. Torchilin, V. Tumor delivery of macromolecular drugs based on the EPR effect. Adv. Drug Deliv. Rev. 2011, 63, 131-135. [CrossRef] [PubMed]

65. Fang, J.; Nakamura, H.; Maeda, H. The epr effect: Unique features of tumor blood vessels for drug delivery, factors involved, and limitations and augmentation of the effect. Adv. Drug Deliv. Rev. 2011, 63, 136-151. [CrossRef] [PubMed]

66. Gaucher, G.; Dufresne, M.-H.; Sant, V.P.; Kang, N.; Maysinger, D.; Leroux, J.-C. Block copolymer micelles: Preparation, characterization and application in drug delivery. J. Control. Release 2005, 109, 169-188. [CrossRef] [PubMed]

67. Tian, H.; Tang, Z.; Zhuang, X.; Chen, X.; Jing, X. Biodegradable synthetic polymers: Preparation, functionalization and biomedical application. Prog. Polym. Sci. 2012, 37, 237-280. [CrossRef] 